\title{
The Effects of Age, Mental Health, and Comorbidity on the Perceived Likelihood of Hiring a Healthcare Advocate
}

\author{
Symone A. McKinnon, BA ${ }^{1}$, Breanna M. Holloway, BA ${ }^{1}$, Maya S. Santoro, MA ${ }^{1,2}$, April C. \\ May, $\mathrm{MA}^{1}$, and Terry A. Cronan, $\mathrm{PhD}^{1}$ \\ ${ }^{1}$ San Diego State University, Department of Psychology \\ ${ }^{2}$ University of California, San Diego (UCSD) /San Diego State University (SDSU), Joint \\ Doctoral Program in Clinical Psychology
}

\begin{abstract}
Background and Purpose: The projected increase in chronically ill older adults may overburden the healthcare system and compromise the receipt of quality and coordinated health care services. Healthcare advocates (HCAs) may help to alleviate the burden associated with seeking and receiving appropriate health care. We examined whether having dementia or depression, along with hypertension and arthritis, or having no comorbid medical conditions, and being an older adult, affected the perceived likelihood of hiring an HCA to navigate the health care system. Method: Participants $(\mathrm{N}=1,134)$, age 18 or older, read a vignette and imagined themselves as an older adult with either a mood or cognitive disorder, and comorbid medical conditions or as otherwise being physically healthy. They were then asked to complete a questionnaire assessing their perceived likelihood of hiring an HCA. Results: Participants who imagined themselves as having dementia reported a greater likelihood of hiring an HCA than participants who imagined themselves as having depression $(\mathrm{p}<.001)$. Conclusion: It is imperative that health care professionals attend to the growing and ongoing needs of older adults living with chronic conditions, and HCAs could play an important role in meeting those needs.
\end{abstract}

(C) 2016 Californian Journal of Health Promotion. All rights reserved.

Keywords: healthcare advocate, aging, dementia, depression, comorbidity

\section{Introduction}

America has over 46 million adults aged 65 or older, most of whom are baby boomers - those born between 1946 and 1964 (Administration on Aging, 2015; Mather, Jacobsen, \& Pollard, 2015). By 2060 that number is projected to reach about 98 million (Mather et al., 2015). Older adults have an increased risk of developing multiple chronic illnesses (Anderson \& Horvath, 2004), and many develop cognitive and mood disorders, including dementia and depression, which negatively impact their physical health (American Psychological Association, 2015; World Health Organization, 2013). Older adults commonly have more complex health care needs, and their health care is often uncoordinated among providers (Anderson \& Horvath, 2004). This requires that the patient, their families, or friends informally coordinate and advocate for their care (Knickman \& Snell,
2002). Older patients may benefit from professional services that provide proper coordination to navigate the complex health care system effectively and efficiently.

Healthcare Advocates (HCAs) are individuals who provide broad categories of services ranging from personal care to coordination of therapeutic modalities and who collaborate with patients and their families to obtain effective care (Wooldridge, Vasserman-Stokes, Cronan, \& Sadler, 2013; Vasserman-Stokes, Cronan, \& Sadler, 2012) and can help reduce the barriers older adults face in navigating the health care system. The present study examined factors affecting the decision to hire an HCA to assist patients in receiving coordinated medical services. More specifically, the purpose of the present study was to determine whether age (70, 80 , or 90 years), presence of a cognitive or mood disorder (dementia or depression), and presence 
of comorbid chronic conditions (hypertension and arthritis or no comorbid condition) affected the reported likelihood of hiring an HCA to provide services for an older adult patient.

The health care system is unprepared to treat and manage the growing number of older adults with chronic health conditions. Therapeutic approaches used to treat acute illnesses are often inappropriately applied to treat chronic diseases (Fani Marvasti \& Stafford, 2012). Although older adults with chronic medical and mental conditions frequent primary care settings, the treatment received for cognitive and mood conditions are often inadequate (Unützer, Schoenbaum, Druss, \& Katon, 2014). Additionally, there is a lack of specialized training in geriatric mental health care within physical health care settings (Bartels, Blow, Brockmann, \&Van Citters 2005; Unützer et al., 2014). Treating comorbid medical conditions in patients with cognitive and/or mood disorders can result in complex medication regimens, nonadherence to prescriptions, and adverse side effects of the medical treatment, which could worsen the cognitive and/or mood disorders (Evans et al., 2005; Schubert et al., 2006). Health care services for patients with chronic conditions are often not properly coordinated amongst multiple health providers (i.e. primary care physicians, specialists, pharmacies, and emergency departments), largely because of lack of inter-professional communication (Vogeli et al., 2007). This leads to an increased risk of medical errors, inefficiency, and unnecessary use of health services (Callahan et al., 2012; Lehnert et al., 2011) and this problem is exacerbated for older adults with multiple chronic conditions (Lehnert et al., 2011; Lynn \& Adamson, 2003, 2006; Anderson \& Horvath, 2004).

Having multiple health conditions within the older adult population is associated with an accelerated decline in health status, increased likelihood of disability (Wolff, Starfield, \& Anderson, 2002), poor quality of life, and mortality (Boyd et al., 2005). It is important to examine those who are most at risk for experiencing poor outcomes to inform the development of prevention and treatment interventions. Two of the most common chronic illnesses affecting older adults are hypertension (high blood pressure) and arthritis. Hypertension, also known as "the silent killer," is asymptomatic, not associated with any bodily warnings, and often goes undetected (World Heart Federation, 2015). Furthermore, while hypertension is treatable if diagnosed and managed properly (World Heart Federation, 2015), unsuccessful management of hypertension is one of the most frequent causes of morbidity and mortality among older adults (Centers for Disease Control, 2012; Marcum et al., 2013). Arthritis, the leading cause of disability among older adults (Hootman, Helmick, \& Brady, 2012), is a chronic musculoskeletal condition characterized by pain, soreness, inflammation, and inflexibility in and around joints and surrounding connective tissues (Hootman et al., 2012). Arthritis is very prevalent among older adults, frequently cooccurs with other chronic illnesses, and leads to increased physical disability, limited functioning, and premature death (Hootman et al., 2012). Hypertension and arthritis are serious chronic conditions that affect a substantial number of older adults and can diminish overall quality of life.

Older adults are also more likely to suffer from cognitive and mood disorders. Depression is a common mood disorder among adults age 65 or older. Depressive symptoms occur in an estimated 15\% of older adults (Funnell, 2010), and this estimate might be an underrepresentation, given the evidence of underreporting. Late-life depression is associated with increased disability, worsened physical health outcomes, and higher mortality rates (Funnell, 2010; Rodda, Walker, \& Carter, 2011). Older adults with depression commonly experience the related stigma, which has been shown to deter many from seeking available and effective treatment (Rodda et al., 2011; Twedell, 2007). It is crucial that depression is identified and treated in this population because it is related to increased suicide rates (Fiske, Wetherell, \& Gatz, 2009; Twedell, 2007), greater disability, and decreased physical, cognitive, and social functioning (Fiske et al., 2009; Langa, Valenstein, Fendrick, 
Kabeto, \&Vijan, 2004).

In 2010, it was estimated that 3.9 million Americans were living with dementia, and these numbers are projected to nearly triple by the year 2050 (Hebert, Weuve, Scherr, \& Evans, 2013; (WHO, 2012). Dementia is among the leading causes of dependency and disability among older adults (WHO, 2012), because it reduces autonomy, limits one's ability to live independently, and impairs engagement in daily tasks (Prince et al., 2013; Sosa-Ortiz, AcostaCastillo, \& Prince, 2012; Wimo, Jonsson, Bond, Prince, \& Winblad, 2013). Treatment is also challenging, because individuals affected by dementia often must adhere to complex medication regimens in order to manage their condition (Arlt, Lindner, Rösler, $\&$ von Renteln-Kruse, 2008). This often leads to frequent medical visits because people with dementia are unable to self-manage their medications (Eaker, Mickel, Chyou, MuellerRizner, \& Slusser, 2002). Moreover, people with severe dementia often cannot make their own medical decisions (Lynn \& Adamson, 2003), which requires that decision-making be transferred to caregivers (Wimo et al., 2013) such as spouses, children, and other loved ones (Knickman \& Snell, 2002).

\section{Healthcare Advocates}

The complex problems facing older adults with chronic medical conditions, late-life depression and dementia could be reduced by an HCA trained in the inner workings of the health care system. HCAs can assist in coordinating both mental and physical health care. They offer a range of supportive and advisory services that include, but are not limited to, scheduling and attending doctor's appointments, informing patients about their diagnoses, coordinating treatment and other health-related services among health providers and medical workers, researching treatment options, offering emotional support, and reducing barriers to gaining access to care (Carlson et al., 2011; Cronan et al., 2010; Wooldridge et al., 2013). The services that HCAs provide are designed to improve patient-provider communication and communication between providers. HCAs are unique because they provide private services, which means their primary allegiance is to the patient who hires them and not to hospitals or insurance companies (Carlson et al., 2011; Wooldridge et al., 2013). Thus, it is important to determine the factors affecting receptivity to the use of HCAs and to identify patients who may benefit most from these services (VassermanStokes et al., 2012; Wooldridge et al., 2013). Previous studies have attempted to identify populations that might be most interested in using the services of an HCA. Researchers have found that ethnicity (i.e. White or Hispanic) (Santoro, Van Liew, Holloway, McKinnon, Little, \& Cronan, 2015), having Alzheimer's disease (Van Liew \& Cronan, 2012), having a severe chronic injury and a pre-existing chronic condition (Santoro, Kothari, Van Liew, \& Cronan, 2014), and having low confidence in the health care system (Cronan et al., 2010) were associated with a greater perceived likelihood of hiring an HCA for a parent or themselves.

\section{The Current Study}

Few studies have examined the impact that cognitive and mood disorders (e.g. dementia and depression) and comorbid chronic conditions (e.g. arthritis and hypertension), have on the perceived need of HCA services. Given that previous findings have clearly demonstrated the risk for poor outcomes among older adults with comorbid physical and cognitive or mood conditions, it is important to better understand the areas of need and solutions for improving health outcomes. Thus, the purpose of the present study was to examine whether being 70 , 80 , or 90 years old, having either dementia or depression, and having hypertension and arthritis, or no medical conditions would affect the perceived likelihood of hiring an HCA.

\section{Methods}

\section{Study Design}

For this study, participants were randomly assigned to one of twelve vignettes, which are described below. The Institutional Review Board of the primary author's university approved the study, and all data were kept confidential. 


\section{Participants}

There were 1,134 people recruited for this study $(M=47.6$ years, $S D=17.7 ;$ Range $=18-92$ years). More than half of the participants were women $(56.1 \%)$ and Caucasian (77.5\%). The majority of the sample had an associate's degree or higher $(85.3 \%)$. Most participants' total annual family income was $\$ 60,000$ or greater $(68.8 \%)$. All participants were treated in accordance with the American Psychological Association's Ethical Principles guidelines (APA, 2010).

\section{Procedure}

Over the course of six months, participants were randomly selected from a large urban cultural park located in southern California. The park attracts thousands of people from diverse ethnic backgrounds and ages. A random number sequence protocol was used to randomly select eligible participants (i.e., who were 18 or older). A team of six research assistants used a random numbers table, with the values ranging from 1 to 5 , to count prospective participants until they reached the $\mathrm{n}^{\text {th }}$ person they would approach. A new number was used only one time for each period of counting to select participants. Potential participants were presented with a cover letter describing the purpose of the study, health care advocacy, eligibility requirements (i.e. speak and read English, be 18 years of age or older), and their participant rights. They were then given a brief survey that included a description of an HCA's role, a vignette, and a related questionnaire to complete. The vignette presented a scenario about an older individual with a cognitive or mood disorder (depression or dementia), and the person was described as either having co-morbid physical conditions (hypertension and arthritis) or no co-morbid health conditions. Participants were asked to imagine themselves as the individual described in the vignette, and to answer ten questions that assessed their perceived likelihood of hiring an HCA for themselves in that scenario. Questionnaires were completed individually and all information provided was kept confidential.

\section{Vignettes}

Participants were randomly assigned to read one of twelve vignette scenarios in which they were asked to imagine themselves as either being 70, 80 , or 90 years of age, having dementia or depression, and having arthritis and hypertension or having no medical problems. Participants read that they had recently been diagnosed with dementia or depression and thus, began to experience associated symptoms (depression: decreased motivation, hopelessness, and low energy; dementia: memory loss and confusion). In the vignette, the person's doctor recommended that he/she seek treatment, and he/she agreed to do so. It was stated that the fictitious person lived alone with no family or friends living nearby. It was also stated that his/her insurance would not cover the costs of hiring an HCA; however, the person was described as having enough money to hire an HCA through his or her own means. The preceding aspects of the story were held constant for all vignette conditions.

\section{Vignette Manipulations}

Cognitive or Mood Disorder. In the vignettes that described the older adult as being recently diagnosed with depression, the person was said to have minimal motivation to complete tasks or do anything other than sleep or watch television. The individual was described as experiencing a sense of hopelessness, low energy, and as experiencing difficulties with concentration and decision making.

In the vignettes describing the older adult as being recently diagnosed with dementia, he/she was described as having severe memory loss and confusion. It was stated that dementia was gradually impacting his/her memory and often made him/her confused. The individual was described as often failing to remember where he/she would place items, when appointments were, and when to take his/her medications. In addition, the person in the vignette was also said to have forgotten to turn off the stove on two occasions.

Comorbid Medical Conditions. In addition to having a cognitive or mood disorder, the older adult in the vignette was either described as being in good physical health or as having hypertension and arthritis in his/her knees and hips. When comorbidity was depicted in the 
vignettes, the person was described as having actively received treatment for his/her physical health conditions over the last 10 years. Additionally, it was stated that his/her high blood pressure required that he/she take medications and follows a custom diet. The individual's arthritis was described as causing him/her considerable pain, hindering his/her ability to engage in physical activities, and requiring him/her to take medications for arthritis. When he/she was otherwise healthy, it was simply stated that he/she was in good health, aside from the cognitive or mood condition.

\section{Measures}

Participants were first asked to rate their understanding of the role of an HCA, using a10point Likert-type scale ranging scale from 1 (not at all) to 10 (a great deal). Then participants were asked, while imagining themselves as the individual depicted in the vignettes, to indicate, using a 10-point Likert scale ranging from 1 (extremely unlikely) to 10 (extremely likely), how likely they would be to hire an HCA to provide ten assistive and advisory services. The ten services included:1) visiting him/her at home to provide additional help with daily activities; 2) visiting $\mathrm{him} / \mathrm{her}$ at home to provide social support; 3) live with him/her in his/her home to provide help with daily activities; 4) accompanying him/her to his/her appointments to provide additional help and support; 5) coordinating his/her medical appointments; 6) informing every member of his/her treatment team of the most recent treatment plan; 7) assisting with daily symptom management; 8) maintaining a file that contained all of his/her medical records; 9) researching treatment options for him/her; and 10) providing assistance in accessing psychological services.

Using a10-point Likert-type scale, ranging scale from 1 (not at all confident) to 10 (extremely confident), participants were asked to rate how confident they were in their understanding of the cognitive or mood condition they were assigned to (i.e. dementia or depression). Additionally, participants were asked to separately rate how much having a cognitive or mood disorder (depression or dementia) and comorbid medical conditions (hypertension and arthritis) influenced their reported decision to hire an HCA, using a10-point Likert-type scale ranging from 1 (not at all) to 10 (a great deal). Lastly, participants were asked to provide their demographic information (age and gender). In addition, they reported their ethnicity by selecting one of the following: Caucasian, African American, Asian/Pacific Islander, American Indian, Latino/Hispanic/Mexican American, or Other (Specify). Participants also reported the highest level of education completed (less than high school, high school graduate, associate's degree/trade school, bachelor's degree, master's degree, or doctoral degree), and their annual family income (below US $\$ 30,000$, US $\$ 30,000$ to US $\$ 59,999$, US $\$ 60,000$ to US $\$ 89,999$, US $\$ 90,000$ to US $\$ 119,999$, US $\$ 120,000$ to US $\$ 149,999$, US $\$ 150,000$ to US $\$ 179,999$, and US $\$ 180,000$ and above).

\section{Analyses}

Preliminary analyses were conducted to ensure that randomization was successful and that participants in the twelve vignette conditions did not significantly differ from each other on any demographic variables. A one-way ANOVA was used to examine participant age in each vignette condition, and a series of chi-square tests was conducted for the following variables: gender (male, female), race (white, racial minority), education (high school degree or less, associate's degree or higher), and household income ( $<\$ 60,000 /$ year, $\geq \$ 60,000 /$ year $)$. A reliability analysis was performed to determine whether the ten HCA hiring questions measured the same dimension. An aggregate variable capturing the overall likelihood of hiring an HCA was created as an average rating of these ten items, which were shown to be highly internally consistent (Cronbach's alpha $=0.946$ ). This average rating of overall likelihood of hiring an HCA, from 1 to 10, was used as the dependent variable in the main analyses. A t-test was performed to examine which cognitive or mood condition had a greater influence on the perceived likelihood of hiring an HCA and whether gender influenced perceived hiring decisions. To examine the role of vignette age, cognitive or mood condition, and presence of 
comorbid disorders on the overall likelihood of hiring an HCA, a 3 (Age: 70 years, 80 years, 90 years) x 2 (Cognitive or Mood Condition: depression, dementia) x 2 (Comorbidity: hypertension and arthritis, no medical conditions) analysis of covariance (ANCOVA) was conducted, controlling for participants' understanding of the role of an HCA and participants' confidence in their understanding of the cognitive or mood condition and gender.

\section{Results}

A one-way ANOVA revealed no significant differences in participants' age across each of the conditions, $F(11,1092)=1.14, p=0.324$. Similarly, a series of chi-square tests showed that participants did not differ across each of the conditions with regards to gender, race, education, and household income. None of the omnibus chi-square tests were statistically significant, $p s>0.05$ (see Table 1). These findings suggest that the randomization procedures were successful and that participants in the 12 conditions did not significantly differ on any sociodemographic variables. T-tests were performed to examine whether having a cognitive or mood disorder in the vignette predicted participants reported likelihood of hiring an HCA. The results indicated that the likelihood of hiring an HCA was significantly greater for participants assigned to a dementia condition $(M=8.97, S D=1.82)$ than for participants assigned to a depression condition $(M=8.02, S D=2.39), t(1140)=7.58 p<0.001$. However, regardless of which of these conditions they were assigned to, participants reported a high perceived likelihood of hiring an HCA $(M>8.0$, on a scale of 1 to 10$)$, suggesting a need for the services provided by an HCA in both conditions. Similarly, for participants who read vignettes in which the individual was described as having comorbid arthritis and hypertension, arthritis was rated as having a greater influence on their reported likelihood of hiring an HCA $(M=6.14, S D=2.55)$ than hypertension $(M=5.79, S D=2.64 ; \mathrm{t}(561)=$ 4.36, $p<0.001)$. Overall, participants assigned to vignettes with comorbid medical conditions indicated that having a cognitive or mood condition had a greater influence on their perceived likelihood of hiring an HCA $(M=$ $8.51, S D=2.21)$ than the medical conditions $(M$ $=5.95, S D=2.42 ; \mathrm{t}(555)=22.07, p<0.001)$. An additional t-test was conducted to examine the effects of gender on the perceived likelihood of hiring an HCA. The results indicated that women reported a higher perceived likelihood of hiring an HCA $(M=7.02, S D=2.22)$ than men $(M=6.52, S D=2.09 ; \mathrm{t}(1130)=-3.871, p<$ $0.001)$.

Participants also reported how well they believed they understood the role of an HCA, using a scale from 1 (not at all) to 10 (a great deal). The results showed that, on average, participants reported having a reasonable understanding of the concept $(M=7.77, S D=$ 2.13). In addition, participants were asked to report how confident they were in their own understanding of the cognitive or mood disorder described in the vignette, on a scale from 1 (not at all confident) to 10 (extremely confident). The average rating of confidence was 7.7 , with a standard deviation of 2.03 .

A 3 (Age: 70 years, 80 years, 90 years) x 2 (Cognitive or Mood Condition: Depression, Dementia) x 2 (Comorbidity: Hypertension and Arthritis, No Medical Condition) ANCOVA was conducted for the overall likelihood of hiring an HCA, controlling for participants' understanding of the role of an HCA, confidence in their understanding of the cognitive or mood condition, and gender. There was a significant main effect for cognitive or mood condition, $F(1,1097)=90.03, p<0.001$. Specifically, participants assigned to a condition in which they imagined they had dementia reported a greater perceived likelihood of hiring an HCA $(M=7.38, S D=1.88)$ than those who imagined they were depressed $(M=6.23, S D=2.30)$. There were no significant main effects for vignette age or comorbidity, and no significant interaction effects. See Table 2 for average ratings of likelihood of hiring an HCA for each of the 12 conditions. 
Table 1.

Participant Sociodemographic Information Stratified by Randomly Assigned Vignette Condition

\begin{tabular}{|c|c|c|c|c|c|c|c|c|c|c|c|c|c|}
\hline & \multicolumn{13}{|c|}{ Vignette Conditions } \\
\hline & $\begin{array}{c}70 \\
\text { Dep. } \\
\text { Health } \\
n=91\end{array}$ & $\begin{array}{c}70 \\
\text { Dem. } \\
\text { Health } \\
\mathrm{n}=100\end{array}$ & $\begin{array}{c}70 \\
\text { Dep. } \\
\text { CMD } \\
\mathrm{n}=95\end{array}$ & $\begin{array}{c}70 \\
\text { Dem. } \\
\text { CMD } \\
n=93\end{array}$ & $\begin{array}{c}80 \\
\text { Dep. } \\
\text { Health } \\
n=97\end{array}$ & $\begin{array}{c}80 \\
\text { Dem. } \\
\text { Health } \\
\mathrm{n}=97\end{array}$ & $\begin{array}{c}80 \\
\text { Dep. } \\
\text { CMD } \\
\mathrm{n}=91\end{array}$ & $\begin{array}{c}80 \\
\text { Dem. } \\
\text { CMD } \\
\mathrm{n}=95\end{array}$ & $\begin{array}{c}90 \\
\text { Dep. } \\
\text { Health } 1 \\
n=93\end{array}$ & $\begin{array}{c}90 \\
\text { Dem. } \\
\text { Health } \\
n=97\end{array}$ & $\begin{array}{c}90 \\
\text { Dep. } \\
\text { CMD } \\
\mathrm{n}=97\end{array}$ & $\begin{array}{c}90 \\
\text { Dem. } \\
\text { CMD } \\
\mathrm{n}=94\end{array}$ & $p$ \\
\hline$\overline{\text { Age (n) }}$ & 89 & 98 & $\overline{95}$ & $\overline{88}$ & $\overline{95}$ & 93 & 87 & $\overline{92}$ & 89 & 94 & 92 & $\begin{array}{ll}92 & 1.14\end{array}$ & 0.32 \\
\hline Mean & 48.19 & 49.99 & 46.61 & 45.81 & 44.88 & 48.41 & 50.15 & 48.85 & 44.62 & 46.26 & 49.93 & 47.04 & \\
\hline SD & 16.95 & 17.58 & 16.68 & 17.48 & 17.74 & 18.53 & 19.14 & 17.73 & 16.49 & 17.41 & 19.35 & 16.96 & \\
\hline Gender (n) & 94 & 97 & 93 & 90 & 97 & 96 & 87 & 88 & 91 & 95 & 93 & 9111.05 & 0.44 \\
\hline Male \% & 35.1 & 38.1 & 46.2 & 40.0 & 50.5 & 50.0 & 39.1 & 46.6 & 40.7 & 49.5 & 44.1 & 46.2 & \\
\hline Female $\%$ & 64.9 & 61.9 & 53.8 & 60.0 & 49.5 & 50.0 & 60.9 & 53.4 & 59.3 & 50.5 & 55.9 & 53.8 & \\
\hline Ethnicity (n) & 93 & 96 & 95 & 90 & 96 & 93 & 88 & 93 & 90 & 95 & 93 & 9171.91 & 0.29 \\
\hline White \% & 71.0 & 84.4 & 76.8 & 74.4 & 74.0 & 77.4 & 76.1 & 81.7 & 73.3 & 81.1 & 80.6 & 79.1 & \\
\hline Education (n) & 93 & 97 & 95 & 91 & 96 & 95 & 89 & 92 & 90 & 96 & 93 & 926.54 & 0.84 \\
\hline $\begin{array}{l}\text { High School } \\
\text { or less } \\
\text { Associate }\end{array}$ & 15.1 & 17.5 & 15.8 & 12.1 & 17.7 & 16.8 & 18.0 & 15.2 & 8.9 & 11.5 & 12.9 & 14.1 & \\
\hline $\begin{array}{l}\text { Associate } \\
\text { Degree or more }\end{array}$ & 84.9 & 82.5 & 84.2 & 87.9 & 82.3 & 83.2 & 82.0 & 84.8 & 91.1 & 88.5 & 87.1 & 85.9 & \\
\hline Income (n) & 85 & 89 & 91 & 81 & 93 & 88 & 85 & 90 & 86 & 89 & 87 & $\begin{array}{ll}88 & 8.90\end{array}$ & 0.63 \\
\hline $\begin{array}{l}\text { Low Income \% } \\
(<\$ 60,000 / y)\end{array}$ & 34.1 & 34.8 & 34.1 & 32.1 & 25.8 & 29.5 & 37.6 & 32.2 & 22.1 & 34.8 & 29.9 & 27.3 & \\
\hline $\begin{array}{l}\text { High Income } \% \\
(>\$ 60,000 / y)\end{array}$ & 65.9 & 65.2 & 65.9 & 67.9 & 74.2 & 70.5 & 62.4 & 67.8 & 77.9 & 65.2 & 70.1 & 72.7 & \\
\hline
\end{tabular}

Note: 70, 80 and 90 refer to the vignette condition age; Vignette mental health status is denoted by Dep. for 'Depression' and Dem. for 'Dementia'; CMD refers to the presence of co-morbid hypertension and arthritis in the vignette and Healthy indicates absence of co-morbid conditions in the vignette.

\section{Discussion}

In the present study, the effects of age, comorbid medical conditions, as well as mood and cognitive disorders were examined to determine their effects on the perceived likelihood of hiring an HCA. To ensure that people understood the variables being examined, it was important to know whether the participants understood the concept of an HCA, dementia, and depression. The findings indicated that participants had moderate to high levels of confidence in their understanding of each. Thus, participants indicated moderate to high levels of confidence in their understanding of the concept of an HCA and the conditions being manipulated. 
Table 2.

Ratings for Likelihood of Hiring an HCA for each Vignette Condition

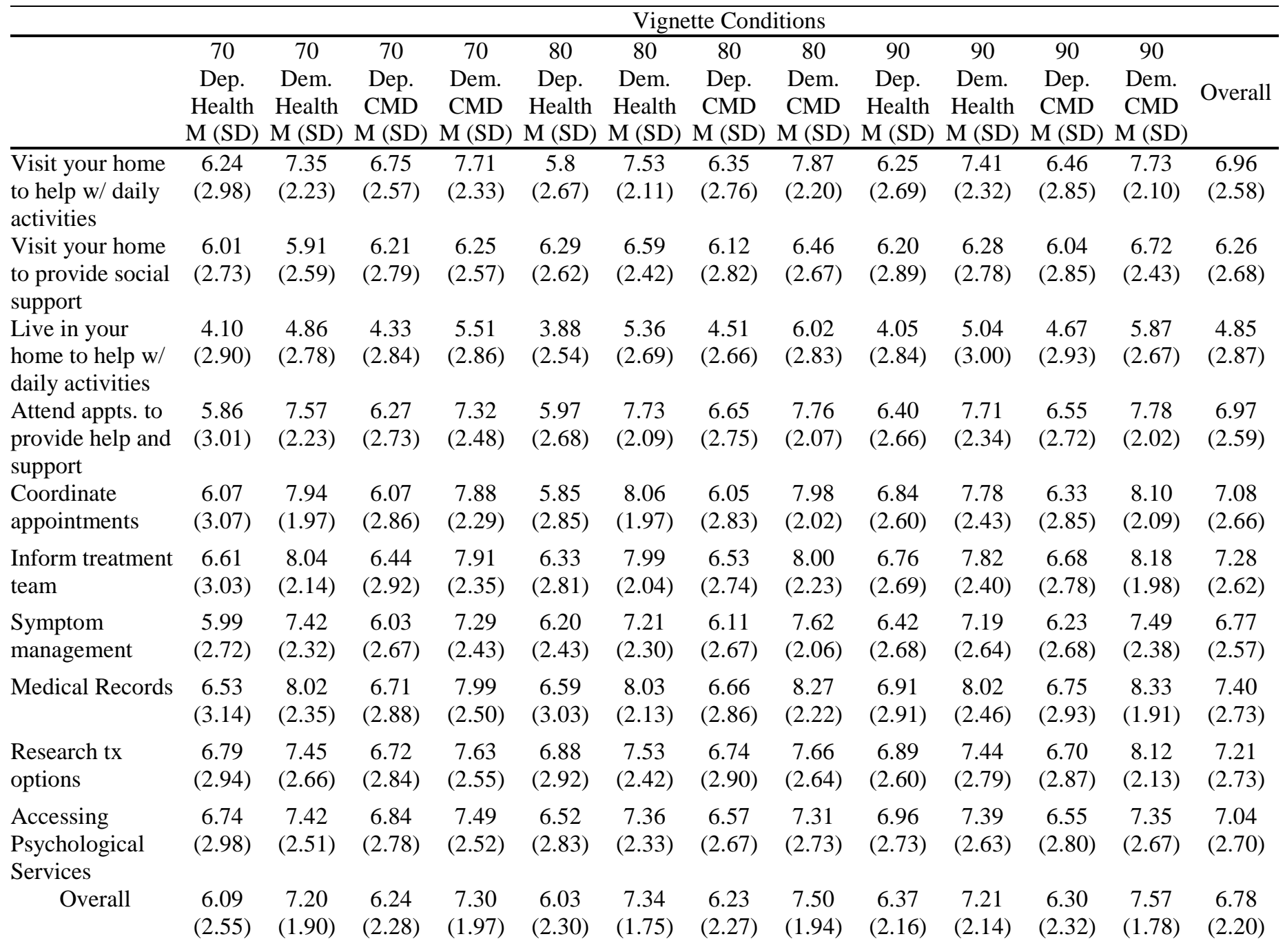

Note: 70, 80 and 90 refer to the vignette condition age; Vignette mental health status is denoted by Dep. for 'Depression' and Dem. for 'Dementia'; CMD refers to the presence of co-morbid hypertension and arthritis in the vignette and Healthy indicates absence of co-morbid conditions in the vignette

Participants who imagined that they had dementia reported a greater perceived likelihood of hiring an HCA than those who imagined they were depressed. One possible reason for this finding is that depression is more likely to be discussed and portrayed in the media than dementia (Stresing, 2010; World Health Organization, 2015). Medications for depression are advertised in the media to be effective in successfully treating the condition, and this is not true for dementia (National Institute of Health, 2011; Substance Abuse and Mental
Health, 2011; Stresing, 2010). Information in the media about dementia tends to be more limited to the scientific findings or advances in the field rather than for its treatment, and currently there is no cure for dementia (WHO, 2015). The results indicated that participants rated dementia as more serious than depression. One possible explanation for this may be that participants believed that dementia resulted in higher health risks and poorer outcomes than depression. However, it is important to note that both conditions resulted in high levels of perceived 
likelihood of hiring an HCA. This finding also suggests that people may perceive a need for special services that HCAs can provide to manage both conditions.

The perceived likelihood of hiring an HCA did not vary as a function of the age of the person portrayed in the vignette. These findings extend those in Santoro et al.'s study (2014), in which people imagined that they were 35 or 80 years old; they found that there was a significantly higher perceived likelihood of hiring an HCA when participants imagined that they were 80 years old than when imagining they were 35 years old. In the present study, older adults were examined more closely by manipulating the age of older people to examine whether there were differences as a function of age after one reaches 70 years old. The findings showed no differences in likelihood of hiring across the 70-, 80-, and 90-year-old conditions; this suggests that there is a perceived need for HCA support over the age of 70 and this effect is constant as age increased to 80 or 90 years old. The findings from both studies indicated a moderate to high likelihood of hiring an HCA for all types of HCA services. This is important because, by the year 2030, one in five people in the United States is expected to be over the age of 65 (Vincent \& Velkoff, 2010) and those who are the oldest are the most likely to need assistance with their physical and mental health conditions. Understanding the impact of age on the likelihood of hiring an HCA will be important in preparing for the impending numbers of older adults.

The results from this study indicated that there were no significant differences in the perceived likelihood of hiring an HCA between individuals with arthritis and hypertension and individuals with no other medical condition. This finding indicates that participants may not have perceived the comorbid medical conditions as requiring additional assistance above and beyond the cognitive or mood disorder. In the Santoro et al. (2014) study, there was a main effect for having a comorbid medical condition; people who imagined having chronic ischemic heart disease reported a higher perceived likelihood of hiring an HCA than people who were healthy. Additionally, Van Liew and Cronan (2012) found that, when participants imagined caring for their older parent who had co-morbid Alzheimer's disease, they had a higher perceived likelihood of hiring an HCA than those who imagined having a parent who was cognitively healthy. Thus, the type of comorbid condition portrayed in a vignette appears to make a difference in the perceived likelihood of hiring an HCA. Further research is needed to more clearly define the parameters of perceived need.

No significant interaction effects were found for age, mood/cognitive disorder, and medical comorbidity. These findings are contrary to Van Liew and Cronan (2012) which found that when participants imagined having a parent who had either a heart attack or a fractured hip and comorbid Alzheimer's disease, they rated their perceived likelihood of hiring an HCA as significantly higher than when the parent had no co-morbid condition (cognitively healthy). In Santoro et al.'s (2014) study, when participants imagined they were 35 years old with a comorbid condition, there was a significantly greater perceived likelihood of hiring an HCA than when they imagined being the same age without a comorbid condition. However, when participants were asked to imagine being 80 years old, there was no significant difference between having a co-morbid condition and not having one. These studies help to define specific idiographic factors that influence the perceived likelihood of help-seeking decisions. Santoro et al.'s (2014) findings indicated that having a physical injury influenced medical decisionmaking in the context of pre-existing medical conditions for younger people, but not for older people. The findings from the Van Liew and Cronan (2012) study and the present study both indicate that having a parent with a cognitive disorder, or having a cognitive disorder yourself, leads to a higher perceived likelihood of hiring an HCA. In both cases, the public appears to consider this condition to be serious and to require additional support services. More research is needed to determine whether people with these types of physical and cognitive conditions would actually hire an HCA for 
assistive services to facilitate navigating the health care system.

\section{Limitations}

The findings from the present study should be viewed within the context of its limitations. In the present study, vignettes were used to manipulate the constructs of interest. The average age of the participants was 47 ; thus, it may have been more difficult for younger participants to imagine that they were 70,80 , or 90 years old than it was for the older participants who were closer in age to those described in the vignettes. In addition, the perceived likelihood of hiring an HCA may differ from the actual decision to hire. The vignettes required participants to imagine that they were wealthy enough to hire an HCA, but this may not have reflected their true financial ability to hire one. In the current study the expense of either hiring a different professional service or using other informal forms of support (e.g. family and friends) to provide comparable services to an HCA were not compared or contrasted. This limits confidence in our knowledge about the process of deciding which services to use. Moreover, previous research has shown that many older adults rely most heavily on informal caregivers, which can include spouses, adult children, and friends, to assist with managing physical conditions, coordinating care, and making important health care-related decisions (McCarty, Hendricks, Hendricks, \& McCarty, 2008).

People functioning as caregivers experience additional burdens that could otherwise be reduced or eliminated with the help and support of HCAs. Thus, HCAs may be better equipped to deal with the health care system. Another possible limitation of the study was that participants who had family members or friends who experienced the situations depicted in the scenarios, may have responded differently than those who did not. Finally, the majority of participants were Caucasian, which may limit the generalizability of the findings. Further research is needed to examine the translation of these hypothetical scenarios into real-life health care decisions.

\section{Conclusion}

This study is important for several reasons. First, researchers, healthcare professionals, and geriatric specialists must understand how older people interact with the physical and mental health care systems to better prepare for the increase in the older adult U.S. population and the demand for healthcare services. Second, the prevalence of chronic physical and mental health conditions is higher in older than younger adults; therefore, more healthcare providers will need to be trained in collaborative and coordinated geriatric care to treat these conditions effectively. Finally, the family members of the aging population may be less able to provide the necessary support, so the services of an HCA will be needed to assist older adults with their healthcare. Thus, it is important to further study the awareness of and the receptivity to HCA services.

\section{Acknowledgement}

This research was supported by the National Institutes of Health, grant number R256M058906.

\section{References}

Administration on Aging (2015). Profile of older Americans: 2015. Administration for Community Living U.S. Department of Health and Human Services. http://www.aoa.acl.gov/Aging_Statistics/Profile/2015/3.aspx

American Psychological Association (2015). Mental and behavioral health and older Americans. Retrieved from http://www.apa.org/about/gr/issues/aging/mental-health.aspx

American Psychological Association (2010). Ethical Principles of Psychologists and Code of Conduct. Retrieved from http://apa.org/ethics/code/index.aspx

Anderson, G. \& Horvath, J. (2004). The growing burden of chronic disease in America. Public Health Reports, 119(3), 263-270. 
McKinnon, S.A., Holloway, B.M., Santoro, M.S., May, A.C., Cronan, T.A./ Californian Journal of Health Promotion 2016, Volume 14, Issue 3, 45-57.

Arlt, S., Lindner, R., Rösler, A., \& von Renteln-Kruse, W. (2008). Adherence to medication in patients with dementia. Drugs \& Aging, 25(12), 1033-1047.

Bartels, S.J., Blow, F.C., Brockmann, L.M., \& Van Citters, A.D. (2005). Substance abuse and mental health care among older Americans: The state of the knowledge and future directions. Rockville, MD: WESTAT.

Boyd, C. M., Darer, J., Boult, C., Fried, L. P., Boult, L., \& Wu, A.W. (2005). Clinical Practice Guidelines and Quality of Care for Older Patients with Multiple Comorbid Diseases: Implications for Pay for Performance. The Journal of the American Medical Association, 294(6), 716-724.

Callahan, C.M., Arling, G., Tu, W., Rosenman, M.B., Counsell, S.R., Stump, T.E., \& Hendrie, H.C. (2012). Transitions in care among older adults with and without dementia. Journal of the American Geriatrics Society, 60(5), 813-820.

Carlson, J.A., Imberi, J.E., Cronan, T. A., Villodas, M.T., Brown, K.C., \& Talavera, G.A. (2011). Factors related to the likelihood of hiring a health advocate. Californian Journal of Health Promotion, $9(1), 62-72$.

Centers for Disease Control and Prevention. (2012). Vital signs: awareness and treatment of uncontrolled hypertension among adults--United States, 2003-2010. Morbidity and Mortality Weekly Report, 61, 703.

Cronan, T. A., Carlson, J. A., Imberi, J., Villodas, M., Vasserman-Stokes, E., \& Dowell, A. (2010). The effects of social support and confidence in the health care system on the likelihood of hiring a health advocate. Psychology Research and Behavior Management, 3, 41-50.

Eaker, E., Mickel, S., Chyou, P., Mueller-Rizner, N., \& Slusser, J. (2002). Alzheimer's disease or other dementia and medical care utilization. Annals of Epidemiology, 12(1), 39-45.

Evans, D. L., Charney, D. S., Lewis, L., Golden, R. N., Gorman, J. M., Krishnan, K. R. R., ... \& Valvo, W. J. (2005). Mood disorders in the medically ill: scientific review and recommendations. Biological Psychiatry, 58(3), 175-189.

Fani Marvasti, F., \& Stafford, R. S. (2012). From sick care to health care-Reengineering prevention into the US system. New England Journal of Medicine, 367(10), 889-891.

Fiske, A., Wetherell, J., \& Gatz, M. (2009). Depression in older adults. Annual Review of Clinical Psychology, 5(1), 363-389.

Funnell, E. (2010). Depression in the elderly. InnovAiT, 3(4), 199-208.

Hebert, L. E., Weuve, J., Scherr, P. A., \& Evans, D. A. (2013). Alzheimer disease in the United States (2010-2050) estimated using the 2010 census. Neurology, 80(19), 1778-1783.

Hootman, J. M., Helmick, C. G., \& Brady, T. J. (2012). A public health approach to addressing arthritis in older adults: The most common cause of disability. American Journal of Public Health, 102(3), 426-433.

Knickman, J. R., \& Snell, E. K. (2002). The 2030 problem: Caring for aging baby boomers. Health Services Research, 37(4), 849-884.

Langa, K., Valenstein, M., Fendrick, A., Kabeto, M., \& Vijan, S. (2004). Extent and cost of informal caregiving for older Americans with symptoms of depression. American Journal of Psychiatry, 161(5), 857-863.

Lehnert, T., Heider, D., Leicht, H., Heinrich, S., Corrieri, S., Luppa, M., ...\& König, H. H. (2011). Review: Health care utilization and costs of elderly persons with multiple chronic conditions. Medical Care Research and Review, 68(4), 387-420.

Lynn, J. \& Adamson, D. M. (2006). Redefining and Reforming Health Care for the Last Years of Life. Santa Monica, CA: RAND Corporation. Retrieved from http://www.rand.org/pubs/research briefs/RB9178.

Lynn, J., \& Adamson, D. M. (2003). Living well at the end of life: Adapting health care to serious chronic illness in old age. Santa Monica, CA: RAND Corporation. Retrieved from http://www.dtic.mil/dtic/tr/fulltext/u2/a416211.pdf

Marcum, Z. A., Zheng, Y., Perera, S., Strotmeyer, E., Newman, A. B., Simonsick, E. M., ...\& Hanlon, J. T. (2013). Prevalence and correlates of self-reported medication non-adherence among older 
McKinnon, S.A., Holloway, B.M., Santoro, M.S., May, A.C., Cronan, T.A./ Californian Journal of Health Promotion 2016, Volume 14, Issue 3, 45-57.

adults with coronary heart disease, diabetes mellitus, and/or hypertension. Research in Social and Administrative Pharmacy, 9(6), 817-827.

Mather, M., Jacobsen, L. A., \& Pollard, K. M. (2015). Aging in the United States. Population Bulletin, $70(2), 1-23$.

McCarty, E., Hendricks, C., Hendricks, D., \& McCarty, K. (2008). Ethical dimensions and filial caregiving. Journal of Health Ethics, 5(1), 1-10.

National Institute of Mental Health. (2011). Depression. Retrieved fromhttp://www.nimh.nih.gov/health/publications/depression/index.shtml?ct=39994\#pub6

Prince, M., Bryce, R., Albanese, E., Wimo, A., Ribeiro, W., Ferri, C. P. (2013). The global prevalence of dementia: A systematic review and meta-analysis. Alzheimer's and Dementia, 9(1), 63-75.

Rodda, J., Walker, Z., \& Carter, J. (2011). Depression in older adults. British Medical Journal, 343(7825), 683-687.

Santoro, M.S., Kothari, D.J., Van Liew, C., \& Cronan, T.A. (2014). Health care advocacy: The relationship between age, chronicity, comorbidity, and perceived need for assistance. California Journal of Health Promotion, 12(3), 46-55.

Santoro, M. S., Van Liew, C., Holloway, B., McKinnon, S., Little, T., \& Cronan, T. A. (2015). Honor thy parents: An ethnic multi-group analysis of filial responsibility, health perceptions, and caregiving decisions. Research on Aging, doi: 10.1177/0164027515598349

Schubert, C. C., Boustani, M., Callahan, C. M., Perkins, A. J., Carney, C. P., Fox, C., ... \& Hendrie, H. C. (2006). Comorbidity profile of dementia patients in primary care: Are they sicker? Journal of the American Geriatrics Society,54(1), 104-109.

Sosa-Ortiz, A., Acosta-Castillo, I., \& Prince, M. (2012). Epidemiology of dementias and Alzheimer's disease. Archives of Medical Research, 43(8), 600-608.

Stresing, D. (2010). Depression in the Media. Retrieved from http://www.everydayhealth.com/depression/depression-in-the-media.aspx

Substance Abuse and Mental Health Service Administration. (2011). Depression and older adults: Key issues. Retrieved from https://store.samhsa.gov/shin/content/SMA11-4631CD-DVD/SMA114631CD-DVD-KeyIssues.pdf

Twedell, D. (2007). Depression in the elderly. The Journal of Continuing Education in Nursing, 38, 1415.

Unützer, J., Schoenbaum, M., Druss, B. G., \&Katon, W. J. (2014). Transforming mental health care at the interface with general medicine: Report for the president's commission. Psychiatric Services, 57(1), 37-47.

Van Liew, C., \& Cronan, T. (2012). Caring for a loved one with Alzheimer's disease: Views from the population about hiring a health care advocate. American Journal of Alzheimer's Disease \& Other Dementias, 27(8), 579-583.

Vasserman-Stokes, E. A., Cronan, T. A., \& Sadler, M. S. (2012). Factors that influence the likelihood of hiring a health care advocate for a chronically ill child. Journal of Pediatric Health Care, 26, $27-$ 36.

Vincent, G. K., \& Velkoff, V. A. (2010). The next four decades: The older population in the United States: 2010 to 2050. Retrieved from https://www.census.gov/prod/2010pubs/p25-1138.pdf

Vogeli, C., Shields, A. E., Lee, T. A., Gibson, T. B., Marder, W. D., Weiss, K. B., \& Blumenthal, D. (2007). Multiple chronic conditions: Prevalence, health consequences, and implications for quality, care management, and costs. Journal of General Internal Medicine, 22(3), 391-395.

Wimo, A., Jonsson, L., Bond, J., Prince, M., \& Winblad, B. (2013). The worldwide economic impact of dementia 2010. Alzheimer's \& Dementia, 9(1), 1-11.

Wolff, J. L., Starfield, B., \& Anderson, G. (2002). Prevalence, expenditures, and complications of multiple chronic conditions in the elderly. Archives of Internal Medicine, 162(20), 2269-2276.

Wooldridge, J. S., Vasserman-Stokes, E. A., Cronan, T. A., \& Sadler, M. S. (2013). Hiring a pediatric health care advocate for advisory and support services. Family and Community Health, 36(2), 125-134. 
World Health Organization. (2015). Dementia Fact Sheet. Retrieved from http://www.who.int/mediacentre/factsheets/fs362/en/

World Health Organization. (2013). Mental health and older adults. Retrieved from http://www.who.int/mediacentre/factsheets/fs381/en/

World Heart Federation. (2015). Cardiovascular disease risk factors. Retrieved from http://www.worldheart-federation.org/fileadmin/user upload/documents/Fact sheets/2012/PressBackgrounder April2012RiskFactors.pdf

Author Information

Terry A. Cronan, $\mathrm{PhD} *$

tcronan@mail.sdsu.edu

phone: 619-594-6915

6505 Alvarado Road Suite 110

San Diego, CA 92120, United States

Symone A. McKinnon, BA

smckinnon814@gmail.com

Breanna M. Holloway, BA

holloway.b.m@gmail.com

Maya S. Santoro, MA

mayasantoro@gmail.com

April C. May, MA

aprilmay32@gmail.com

*corresponding author 